\title{
Vida, luta e Movimento pela Saúde dos Povos no Brasil: entrevista com Irmã Anne Whibey
}

\author{
Life, struggle and People's Health Movement in Brazil: interview with \\ Sister Anne Whibey
}

Marta Giane Machado Torres, $\mathbf{1 , 2 , 3}$, Átila Augusto Cordeiro Pereira4, Tânia Sena Conceição ${ }^{\mathbf{5 , 6},}$ Valdirene Barroso Miranda ${ }^{\mathbf{1}} \mathbf{7}$, William Dias Borges ${ }^{\mathbf{8}}$

DOI: 10.1590/0103-11042020S116

'Secretaria de Estado de Saúde Pública do Pará (Sespa) - Belém (PA), Brasil.

martagianetorres@gmail. com

2 Fórum de Mulheres da Amazônia Paraense (FMAP) - Belém (PA),

Brasil.

${ }^{3}$ Movimento pela Saúde dos Povos/Norte Brasil (MSP) - Belém (PA), Brasil.

${ }^{4}$ Universidade Federal do Pará (UFPA), Programa de Pós-Graduação em Saúde, Ambiente e Sociedade na Amazônia (PPGSAS) Belém (PA), Brasil.

${ }^{5}$ Conselho Estadual de Saúde (CES) - Belém (PA), Brasil.

6 Movimento de Mulheres do Campo e da Cidade do Estado do Pará (MMCC/ $P A)$ - Belém (PA), Brasil.

7 Secretaria Municipal de Saúde (Sesma) - Belém (PA), Brasil.

8 Universidade do Estado do Pará (Uepa) - Belém (PA), Brasil.
RESUMO Este texto foi escrito a partir de uma entrevista com a ativista do Movimento pela Saúde dos Povos (MSP), Anne Caroline Wihbey, Irmã da Congregação Notre Dame de Namur, norte-americana de ascendência libanesa, com reconhecida trajetória no desenvolvimento social no estado do Maranhão. Aos 95 anos, camarada e amante de todas as lutas por dignidade e justiça, mantém-se ativamente firme, com o 'pé na estrada'. Entre viagens rodoviárias Belém/São Luís/Belém, atualmente, está empenhada em organizar o seu arquivo pessoal sobre a história do MSP, em geral, e do Maranhão, em particular. Depois disso, costuma dizer 'que pode desaparecer'. Sempre envolvida no trabalho de educação popular, sobre os malefícios resultantes dos megaprojetos junto à vida da população, reitera afirmativamente que saúde e meio ambiente não são mercadorias. Avante na ação mobilizadora, a Irmã segue ciente de sua idade avançada, congregando esforço em aceitar seus limites com alegria e determinação. Este artigo é baseado em conversas com Irmã Anne, que abordaram sua história, sua vinda dos Estados Unidos para o Brasil e a sua vinculação ao MSP desde os primórdios, além de relatar o seu trabalho para cultivar o MSP no Brasil, passando pela experiência de formação de grupos em Nina Rodrigues e em São Luís, no Maranhão, e de incentivo à construção do MSP em Belém do Pará.

PALAVRAS-CHAVE Educação em saúde. Participação da comunidade. Biografia.

ABSTRACT This text was written from the interview with People's Health Movement (PHM) activist Anne Caroline Wihbey, Sister of the Notre Dame de Namur Congregation, an American woman of Lebanese ancestry, with a recognized trajectory in social development in the state of Maranhão, in northeastern Brazil. At the age of 95, a comrade and lover of all struggles for dignity and justice, she stands firmly on the road. Between road trips Belém/São Luís and São Luís/Belém, currently, she is committed to organizing her personal archive on the history of PHM, in general, and in Maranhão, in particular. After doing that, she often says she 'can disappear'. Always involved in the work of popular education, approaching the harms resulting from megaprojects in the life of the population, she reaffirms that health and environment are not commodities. Moving forward in the mobilizing action, Sister Anne continues to be aware of her advanced age, gathering effort to accept her limits with joy and determination. This article is based on conversations with Sister Anne, building a story about her history, her coming from the United States to Brazil and her connection to the PHM from the earliest days, as well as reporting her work to cultivate the PHM in Brazil, through the experience of forming groups in Nina Rodrigues and São Luís, in the state Maranhão, and encouraging the construction of the PHM in Belém, Pará.

KEYWORDS Health Education. Community participation. Biography. 


\section{Introdução}

Irmã Anne, 95 anos, pessoa comprometida com as lutas sociais, conversou com os autores do presente estudo sobre o Movimento pela Saúde dos Povos (MSP). Ao longo de vários encontros em Belém (PA), cidade onde sua Congregação, Irmãs Notre Dame de Namur (SNDdN), tem morada fixa, a ativista social falou sobre sua trajetória de lutas por dignidade, sempre ao lado do povo. O roteiro inicial fora programado com algumas perguntas, a fim de conduzir o diálogo, que seria gravado. Mas a interlocutora deu outro tom e preferiu garimpar seu arquivo pessoal e esmiuçar cada registro, seja de fotografias ou de escritos em agendas, folhas avulsas e relatórios emitidos à sua SNDdN. Além do material físico, sua memória predominou. As informações que necessitavam de complementação foram enviadas posteriormente via aplicativo de celular. Ir. Anne trabalhou exaustivamente, levantando material com informativos desde sua chegada ao Brasil.

Atualmente, Ir. Anne vive em Belém, devido ao fechamento da Congregação, em 2018, tendo deixado em São Luís o acervo de toda sua vida na luta. Conta que seu coração também ficou no Maranhão, junto ao povo; por isso, e pela necessidade de concluir as buscas dos materiais em seu acervo, viaja frequentemente. Enfatiza ser uma pena não poder aprofundar suas buscas para conseguir uma melhor forma de incorporar detalhes dos trabalhos nos anos iniciais do MSP. Lamenta não poder nominar todas as pessoas que muito contribuíram para a construção desse movimento. Os registros aqui presentes são resultado das suas garimpagens pesquisadas e relatadas.

\section{Chegada e partida do Brasil, sua Congregação e a luta por dignidade}

Em 1971, Ir. Anne chegou ao Maranhão/Brasil. No ano seguinte, foi para o Rio de Janeiro, onde dedicou-se ao estudo da língua portuguesa, contexto histórico, geográfico e sociopolítico. Depois seguiu para São Luís do Maranhão, no Nordeste brasileiro. Graduada em enfermagem e pedagogia, passou a trabalhar, junto às Irmãs de Notre Dame, nas comunidades e no centro de formação de técnicos de enfermagem. Desenvolveu vários trabalhos de formação político-popular. Recorda que, em 1981, sob o lema da Campanha da Fraternidade 'Saúde para Todos', esteve envolvida de corpo e alma numa missão pedagógica com a Igreja Católica.

Após 12 anos de intenso trabalho em nome da justiça social, viajou para a Nicarágua. Lá, somou-se às ações revolucionárias brigadistas, especificamente àquelas de educação popular sobre questões sanitárias. Diz que, no princípio desse trabalho, os médicos tinham dificuldade de interagir com o pessoal em formação, mas que, nos dois anos de caloroso estudo, essa relação sandinista progrediu exitosamente.

Sua Congregação Notre Dame mantinha interlocução ativa com o avanço revolucionário, juntamente às diversas organizações parceiras, como Cusclin (Cidadãos Americanos que moram na Nicarágua) e Cisas (Centro de Informação e Serviços de Assessoria em Saúde), este fundado e coordenado por Ana Quirós e Maria Hamlin Zúniga, com quem Ir. Anne comunga a luta pela saúde dos povos até hoje.

Na Nicarágua, viveu intensamente cada etapa, em particular, no setor rural, entre os assalariados agrícolas das montanhas. Atualmente, lamenta muito que a Nicarágua tenha apagado toda a revolucionária luta e esteja a massacrar seu povo. Além dessa vivência, sempre sob os desígnios de Notre Dame, contribuiu para a educação popular na Nigéria, regressando ao Brasil no final dos anos 1999.

\section{Retorno ao Brasil: engajamento e ativismo em conexão com o MSP}

Seguindo as virtudes e o carisma da Congregação para trabalhar com os pobres 
em locais mais abandonados, Ir. Anne diz que todo o trabalho com o povo deve ser o de exigir e influenciar os governantes e os políticos a assumirem e cumprirem suas responsabilidades frente ao cuidado com a saúde da população. $O$ povo deve fazer valer o acordo consagrado em Alma-Ata ${ }^{1}$ - que obriga todos os governos a promover a Atenção Primária à Saúde (APS) -, deixando bem claro que existe grande diferença entre tarefas e responsabilidades, que a população tem o direito e o dever de participar no planejamento e na execução dos cuidados de saúde.

Pela Congregação, esteve em reuniões e articulações nas agendas globais junto à Organização Mundial da Saúde (OMS). Localmente engajada com os movimentos sociais, como MST (Movimento dos Trabalhadores Sem Terra) e CEBs (Comunidades Eclesiais de Base), seguiu na mobilização contra as injustiças. Com o trabalho em saúde popular, percorreu inúmeros municípios e, em Alcântara, concentrou esforços junto aos grupos de mulheres, lutando com as famílias atingidas pelas obras da Base de Lançamentos. Diversas comunidades quilombolas foram retiradas de seu lugar de moradia, com desapropriação de territórios tradicionais pelo governo para servir ao programa aeroespacial, fato este denunciado pelos movimentos sociais na Organização Internacional do Trabalho (OIT).

Pela Arquidiocese, Ir. Anne integrou a Comissão de Justiça e Paz e o Movimento Reage São Luís, em defesa do meio ambiente frente à ação danosa da Mineradora Vale. Atuou junto aos demais movimentos, reforçando a importância da educação do povo sobre os malefícios que a implantação de megaprojetos suscitava na vida da população e do planeta. Naquele tempo, lembra que recebeu uma mensagem de Maria Zúniga, anunciando o processo de preparação para a I Assembleia do
Movimento pela Saúde dos Povos (I AMSP), a ocorrer no Sul da Ásia. Mobilizou-se para levar mais pessoas consigo para esse evento, realizando campanha de arrecadação de fundos, com contribuição até da prefeitura, o que garantiu a ida de Maria Ivana Cesar e Maria Vitória Santos. Assim, em 2000, as três ativistas firmaram laços fraternos e solidários entre Brasil e MSP em Dhaka, capital de Bangladesh.

\section{MSP no Brasil: a luta pela saúde dos povos}

Ir. Anne relata que ficou impressionada com a motivação presente nos ativistas reunidos na Assembleia Mundial de Saúde dos Povos (I AMSP), em Bangladesh, no ano 2000. Representantes de movimentos sociais de todo o mundo manifestavam uma compreensão coletiva de que saúde não é mercadoria e do compromisso em defesa dos mais necessitados. A delegação brasileira levou vários materiais para montar um 'estande brasileiro amazônico bem maranhense'. Pautou nessa Assembleia os sérios problemas existentes na vida dos povos quilombolas com a implantação do Centro de Lançamentos em Alcântara. Ressalta, contudo, que a situação com a Base Espacial hoje é ainda mais difícil do que naquela época.

Desde então, Ir. Anne apresenta a Carta pela Saúde dos Povos $^{2}$ em cada canto por onde passa. Promoveu a tradução de todos os escritos produzidos durante e após a Assembleia. Em todas as lutas a partir de então, leva consigo o slogan do MSP. Apresenta registros escritos e fotográficos abundantes. Conforme seu pedido, segue seu relato sobre a I AMSP, emitido à sua Congregação no ano 2000, traduzido pelos autores do original em inglês, destacado no quadro 1, e a síntese da Carta pela Saúde dos Povos feita por Ir. Anne, no quadro 2. 
Quadro 1. Carta à Congregação

Queridas irmãs,

Saudamos vocês com um caloroso abraço e queremos compartilhar uma excepcional, rica e significativa experiência que pode incluir todas nós.

A Assembleia de Saúde do Povos (sigla PHA, em inglês), realizada em Bangladesh, de 4 a 8 de dezembro de 2000, reuniu cerca de 1500 pessoas de quase 100 países de todo o mundo. Tive o privilégio de ser uma dos 30 participantes dos 10 países da América Latina nesse grande evento.

Durante um período de 10 anos, oito ONGs juntaram recursos para criar, organizar, coordenar e patrocinar esta oportunidade incomum de reunir, vindos de todos os cantos da Terra, amantes da vida, comprometidos com a luta por justiça e paz: saúde para todos. Pela primeira vez, uma plataforma internacional foi aberta para vozes inéditas de base.

Foram convidados, para ouvir essas vozes e responder, muitos profissionais e especialistas de diversas áreas, como saúde, educação, economia, ecologia, agronomia, biodiversidade, análise social. E até mesmo políticos de alguns governos. A presença das mulheres era notável. Foi uma reunião colorida e inspiradora, que ensejou o intercâmbio entre diversas culturas e religiões do mundo. Todos os continentes tiveram representação.

A dinâmica e o intercâmbio de experiências ultrapassaram os limites do tempo e da imaginação através do impressionante despertar da consciência global a partir das experiências locais.

Muito ansiosa no sentido de fazer uma síntese de todas as questões, eu gostaria apenas de compartilhar alguns dos resultados que aparentemente tocam à missão da Notre Dame em todos os lugares:

- Questões antes não respondidas (a nível nacional ou internacional) foram ouvidas, obtiveram apreciação, resposta e orientação.

- Foram contados mais de 400 testemunhos, histórias e apresentações dos quatro cantos do mundo.

- Indígenas, refugiados, sem-terra, vítimas do sistema racial e de castas, fisicamente mutilados, agentes comunitários de saúde, agricultores, trabalhadores e desempregados foram reveladores em suas expressões de sofrimento, enquanto lutavam para criar métodos de sobrevivência e programas de promoção da saúde nas comunidades. Os sistemas de saúde falham e muitas vezes deixam de contemplar as populações mais pobres. Ouviram-se, portanto, seus apelos por apoio internacional.

- Assumiu-se o compromisso de unir todos os esforços locais em uma força global para minorar as injustiças concernentes tanto ao sistema econômico, quanto ao sistema de saúde, injustiças essas, que oprimem os pobres em todos os países. A capacitação dos movimentos de base oferece energia e coragem para a participação da comunidade em tempo integral.

'Desunidos nós imploramos; unidos nós exigimos'.

- A Assembleia marca o início de um novo movimento internacional de solidariedade pela mudança. A criação de um Centro Internacional de PHA para a continuidade do processo iniciado está em andamento.

- A saúde é um direito humano: todas as pessoas, independentemente de cor, origem étnica, religião, sexo, idade, habilidades, orientação sexual ou classe, têm direito a uma VIDA com dignidade.

- Ênfase em 'Pessoas, Não Lucros'. Enfatiza-se claramente o impacto negativo das ações empreendidas pela Organização Mundial do Comércio (OMC), pelos Direitos de Propriedade Intelectual Relacionados com o Comércio (sigla Trips, em inglês), pelo Banco Mundial, pelo FMl e pelas Empresas Transnacionais (sigla TNC, em inglês), com seu acordo comercial que produzirá medicamentos completamente fora do alcance dos pobres do mundo, assim como se destacam outras implicações negativas na saúde das pessoas.

A PHA se compromete a exigir alterações no acordo Trips com vistas a assegurar que todos os indivíduos tenham acesso à medicação necessária.

- O importante aprimoramento da educação, que enseja uma melhor compreensão das causas dos sistemas opressivos de saúde, será parte do processo em curso, de modo que as estratégias desenvolvidas no processo de transformação possam resultar em benefícios permanentes para os pobres do Sul e do Norte.

'Os filósofos só interpretaram o mundo; a questão é mudá-1o'.

- Poder do Povo:

'A história nos ensina que, quaisquer que tenham sido as mudanças que ocorreram, foram através do povo'.

'Nós alcançamos isso (mudança social) não por métodos convencionais, mas através da mobilização de base'.

'A comunidade deve ser um ator participativo no sistema de saúde, pois este é para ela tanto projetado quanto dirigido'.

Ani C. Wihbey, SND (Brasil) ASSEMBLEIA DE SAÚDE DOS POVOS - 2000

GONOSHASTHAYA KENDRA BANGLADESH

Fonte: Carta pela Saúde dos Povos². 
Quadro 2. Comentários sobre a Carta pela Saúde dos Povos (People's Health Charter - PHC)

Deu-se oportunidade à plena participação no desenvolvimento da Carta pela Saúde dos Povos. Embora alguns aspectos da Carta não tenham atendido à expectativa de cada indivíduo, ela foi endossada pela Assembleia.

A PHC valoriza o Declaração de Alma-Ata de 1978, obrigando todos os governos a promover a Atenção Primária à Saúde (APS)

para que, em 2000, a Saúde para Todos se tornasse realidade.

Como vocês sabem esse sonho não se tornou realidade.

A Carta é um apelo a todos os governos e organizações, locais, regionais, nacionais e internacionais, seculares ou religiosos, bem

como a todos os povos para que compartilhem a visão de um mundo melhor através da participação ativa no processo de PHA

para justiça em todos os níveis.

A Carta descreve a visão, a crise global de saúde e seus princípios. O apelo à ação inclui:

- Saúde como um direito humano;

- Enfrentar os determinantes mais abrangentes da saúde;

- Desafios Econômicos;

- Desafios sociais e políticos:

- Guerra, violência e conflito;

- Um setor da saúde centrado no povo;

- Participação das pessoas por um mundo saudável.

Fonte: $\mathrm{PHM}^{3}$.

A entrevistada enfatiza que, a partir da $1^{a}$ Assembleia MSP, as participantes trabalharam firme nas comunidades locais, promovendo o conceito de Alma-Ata, entendendo que, para se ter saúde, era e é necessária a intervenção de muitos outros setores, sociais e econômicos, além do setor saúde. Com material traduzido e reproduzido, também comunicaram em rádios comunitárias. Naquele tempo, além de São Luís, o trabalho formativo avançou pelo interior do Ceará, na comunidade de Poça da Onça (hoje pertencente à Miraíma). Aí foram desenvolvidos os primeiros estudos da Carta pela Saúde dos Povos ${ }^{2}$, fortalecendo a luta e a solidariedade com o povo, pelos direitos em saúde e pela própria vida. Entre os desafios que vieram pela frente, ficaram firmes na luta contra a adesão do governo brasileiro à Alca (Área de Livre Comércio das Américas).

\section{O MSP em conexões com a voz daqueles que não são ouvidos}

Alcântara pertence à Amazônia, rica em biodiversidade e recursos naturais. Parte do território foi expropriada em 1980, e famílias descendentes de indígenas e quilombolas tiveram suas vidas prejudicadas. As áreas para onde foram remanejadas eram impróprias para agricultura e pesca. As comunidades e os movimentos travaram mobilizações contra o avanço da miséria do povo. Durante o plebiscito nacional da Alca, vestidos com a logomarca do MSP, em São Luís, vários ativistas incansavelmente consultaram e conversaram com o povo. Foram 3.894 municípios, totalizando 10.149 .542 pessoas contrárias às questões ali levantadas 'Não à Alca!'. Ir. Anne mostra ainda uma réplica da cédula, afixada em sua agenda de 2002 .

Em 2003, relembra que participou do Fórum Social Mundial ocorrido em Porto Alegre, Rio Grande do Sul. Encontro que foi resultado das resistências locais e regionais, em oposição à submissão da América Latina aos países ricos. Destaca que a longa luta contra a Alca foi muito dura. Como MSP, compôs a delegação que partiu do Maranhão, com os Movimentos Inter-religiosos, Comissão Pastoral da Terra (CPT) e MST. O cenário político marcava a importância do novo governo, sendo o primeiro Fórum após a posse de Lula, do Partido dos Trabalhadores (PT), como Presidente da República. Levou material do MSP para as oficinas, bem como várias cópias da Carta pela Saúde dos Povos. Relata que aquele ano 
marcou o início da era dos governos de esquerda na América Latina. Evento mundial de esperança, autonomia e soberania dos povos.

Pelo MSP, Ir. Anne refere que fez muitos intercâmbios. Considera-se uma 'conectadora', termo que usa para falar das inúmeras ligações que cultiva em favor da luta por justiça social. Sempre trabalhou em equipe, gosta de fazer alianças com muitos grupos, dos quais fazem parte pessoas que se destacam nos diuturnos trabalhos, como Zaira Sabry Azar e José Jonas Borges da Silva, ambos ligados à educação no campo. Junto a eles e tantas outras boas gentes, mantém estreitos laços pela educação libertadora.

Segue camarada e amante de todas as lutas sociais e ambientais. Tem um profundo fascínio por escutar a voz daqueles que não são ouvidos. Acrescenta que, juntamente com o Padre João Maria Van Damme, da ASP-MA (Associação de Saúde da Periferia do Maranhão), investiu energias por uma Igreja participativa e solidária com as dores do povo, e com Ir. Lilis, em Marabá (PA), somou com trabalhos comunitários de formação política em saúde. Rememoriza que, quando hospitalizada, foi presenteada com uma bandeira do MST assinada pela militância, que torcia por sua breve recuperação.

Entre os documentos que selecionou para compor este artigo, consta que o MSP, junto com a Sociedade Maranhense de Direitos Humanos (SMDH), o MST, o Centro de Defesa Marcos Passerine, o PT e Quilombo Urbano, firmaram solidariedade com as três freiras ativistas nos EUA, ao combater os efeitos das bombas nucleares e da radiação no meio ambiente. Ir. Anne diz que essas bravas mulheres foram presas porque viviam sua fé envolvidas em questões de justiça social. Para ela, as Irmãs dominicanas Jackie Hudson, Carol Gilbert e Ardeth Platte expressam que quaisquer tipos de armamentos ameaçam o ser humano, principalmente os de efeito genocida.

Outro documento, o Relatório de Atividades do Projeto de Saúde do Povo do CMO (Congregational Mission Office)/SNDdN, emitido por Ir. Anne em São Luís (MA), em
2005, versa sobre os difíceis desafios frente aos prejuízos à vida e à saúde (física e mental) do povo que permanece excluído pelo projeto das indústrias siderúrgicas transnacionais e pelo complexo siderúrgico na ilha. Aponta que os movimentos intensificaram esforços para acompanhar as comunidades através de atividades educativas. Graças ao apoio da CMO, o MSP do Maranhão esteve na segunda Assembleia Mundial de Saúde dos Povos (II AMSP), em Cuenca (Equador), em 2005. Nesse evento, cooperadores da educação popular apresentaram o intenso trabalho desenvolvido no Nordeste do Brasil para promover a saúde dos povos e proteger o meio ambiente. No referido relatório, informa-se que Irmã Dorothy Stang foi assassinada em 12 de fevereiro, no Pará. Ela atuava junto com os trabalhadores rurais na área da rodovia Transamazônica, no combate aos conflitos fundiários e em defesa do meio ambiente. Como bem diz Ir. Anne, suas vidas seguem a enfrentar as injustiças como Irmãs de Notre Dame.

Seguindo seus registros fotográficos, veemse: caixão, castiçais, crucifixo, velas e o morto - São Luís (1612 a 2007). Nesse cenário, está, entre estudantes, Ir. Anne, vestida de camiseta preta com a inscrição 'Apoio', conforme sua explanação, uma negação ao Polo Siderúrgico, este que vem provocando chuva ácida, destruição dos manguezais, emissão de poluentes, adoecendo até a morte o ecossistema. Em meio às imagens, é possível ver folhetos explicativos com rios e silhuetas em agonia projetando nomes das transnacionais e seus exorbitantes lucros. Reporta um trabalho da professora Lúcia Regina Nascimento, com seus alunos do Instituto Federal do Maranhão. Esta e sua mãe faziam parte das comunidades envolvidas na defesa da ilha. Ao rememorar, a Irmã assinala que há profunda simbiose nas lutas entre sua Congregação e o MSP - se há justiça social e ambiental, há saúde!

Fruto das inúmeras conexões, em 2007, ela recebeu o título de cidadã maranhense - promovido pelo mandato da Deputada Estadual Helena Heluy (PT), por sua contribuição ao 
desenvolvimento social. Pelos 30 anos do MST, em 2014, esteve entre as pessoas homenageadas. Consta no site eletrônico do MST:

Irmã Anne é uma lutadora da Congregação de Notre Dame. Escolheu o Maranhão como sua terra. Lutadora internacional da saúde, terra, água, moradia, trabalho, cultura, alegria e amor. Mulher defensora das crianças e jovens, dos povos negros, indígenas e sem terra ${ }^{4}$.

\section{MSP em Nina Rodrigues, jornada de formação de ativistas no Nordeste brasileiro}

O processo de formação do MSP em Nina Rodrigues/MA (área que congrega comunidades rurais) foi iniciado em 2012. Num desdobramento da Campanha da Fraternidade, cujo lema era 'Fraternidade e Saúde Pública', Ir. Anne negociou com a paróquia mais tempo para aprofundar os sentidos entre fraternidade e luta por saúde no seu termo mais amplo. Atualmente, o MSP de Nina Rodrigues conta com os ativistas: Claudenir Gomes da Silva, Marcelo Silva Almeida e Maria de Jesus Farias Santos como seus principais animadores. Ir. Anne, que, desde o início, mantém fortes laços na construção do MSP, foi responsável por sua movimentação e seu conhecimento teórico. Ia regularmente até Nina Rodrigues para reuniões, encontros e estudos. Preparou extenso material didático adequado à realidade local, adotou metodologia utilizada pelo grupo para trabalhar como equipe de saúde, incorporando o processo de formação para além do objetivo próprio de uma campanha.

Entre 2013 e 2015, centrou na exploração de conteúdos que subsidiassem situá-los no contexto local e fazer sua conexão com a conjuntura mais abrangente no plano das estruturas que sustentam a sociedade. Por dois anos, os ativistas aprofundaram conhecimentos sobre os desafios para se viver dignamente, com disposição para se contrapor a qualquer tipo de injustiça. Ao final da formação, compartilhada também por outros instrutores, foi organizada cerimônia para receberem certificados de ativistas do MSP.

Nos encontros periódicos, planejaram continuar reuniões com as comunidades e a aproximação com a gestão municipal, no intuito de reivindicar melhorias nas infraestruturas locais. Participaram de eventos na capital, custeando despesas através de fundos solidários. Em 2016, o MSP de Nina Rodrigues participou ativamente do Encontro do MSP Brasil em São Luís (MA), organizado pela Ir. Anne e coordenado pelos demais colaboradores. Estiveram presentes ativistas do MSP de Porto Alegre (RS), São Luís (MA), Rio de Janeiro (RJ), São Paulo (SP), Brasília (DF) e de Belém (PA). Dois representantes do MSP internacional também estiveram presentes: Maria Zúniga, da Nicarágua, e Gabriel Vatik, do México.

Nesse encontro, o MSP de Nina Rodrigues teve oportunidade de se conectar amplamente com ativistas agregados a várias expressões de luta da América Latina. Inclusive estreitaram elos com os movimentos sociais locais: Justiça nos Trilhos, Núcleo de Extensão e Pesquisa com Populações e Comunidades Rurais, Negras, Quilombolas e Indígenas (NuRuNi) da Universidade Federal do Maranhão (UFMA), Via Campesina/MST, Grupo de Estudos Desenvolvimento, Modernidade e Meio Ambiente (GEDDMA/UFMA) e o 'Jornal Alternativo Vias de Fato'. No entendimento de Ir. Anne, as contribuições das oficinas de formação fortaleceram e vêm embasando todas as suas atividades de luta cotidiana pelo bem viver, conforme o trecho da Carta pela Saúde dos Povos:

Desafios do meio ambiente [...] Poluição da água e do ar, rápidas mudanças climáticas, destruição da camada de ozônio, energia e lixo nucleares, produtos químicos tóxicos e pesticidas, perda da biodiversidade, devastação de florestas e erosão do solo têm ampla consequência na saúde das pessoas ${ }^{2(9-10)}$. 


\section{Estreitos laços entre MSP/ MA e MSP/PA}

Em novembro de 2015, a Irmã articulou várias reuniões em torno do MSP nordestino. Num primeiro momento, junto ao grupo de articulação MSP/urbano, na UFMA, no espaço do NuRuNi, com pessoal oriundo de vários outros movimentos sociais e da universidade. A pauta: existência e finalidade do MSP.

Circularam informes sobre a audiência para revisão do plano diretor, que propunha transformar a zona rural do município em área industrial, e permissão para construção de prédios com mais de trinta andares na ilha. Os movimentos eram contra essas medidas, visto que a poluição industrial já ultrapassara todos os indicadores recomendados pela OMS e pela legislação brasileira ${ }^{5}$. Na pauta sobre o MSP, entre outras questões, o diálogo se estabeleceu em torno da política de saúde pública no Brasil e da sistemática ameaça de privatização do Sistema Único de Saúde (SUS). Também quiseram saber por que o MSP fora financiado pela Fundação Rockefeller. Essa mesma questão emergira no curso de ativistas da Universidade Internacional Saúde dos Povos (IPHU), promovido pelo MSP em Porto Alegre, em 2008. A resposta foi que se tratava de uma causa afirmativa, no caso, para a luta pela saúde enquanto direito universal, e que o financiamento da Fundação não tinha nenhuma marcação, ou seja, poderia ser usado da forma como o MSP acreditasse ser melhor.

Para chegar até Nina Rodrigues, localidade periurbana, são quase quatro horas de viagem. Nos assentamentos de Vila Esperança e Palmares, aconteceram as reuniões e os estudos. Num ambiente de muitas árvores, os moradores foram chegando e se sentando sob as mangueiras. Representantes conversaram sobre seus problemas cotidianos, dos assassinatos e da violência aos trabalhadores da terra, e sobre falta de uma escola na sua área de morada. Discutiram estratégias de mobilização.

No outro dia, o MSP de Nina Rodrigues se reencontrou. Falaram do que vinham desenvolvendo em suas comunidades, das discussões sobre o que aglutinava o povo para garantia de direitos. Foram compartilhadas visões sobre a III Assembleia Mundial do MSP e sobre as articulações que vinham acontecendo em defesa da saúde para todos e todas. O grupo registrou que a formação e os estudos que obtiveram, facilitados pela Ir. Anne e seus colaboradores, valeram muito para compreenderem que a saúde é muito mais do que o foco sobre a doença, entendendo também ser importante unir forças com as demais lutas.

\section{MSP e os povos da Amazônia, a luta continua!}

O MSP Brasil compôs a grande delegação do MSP América Latina, presente no Fórum Social Mundial/2009, em Belém (PA). Junto a esse agrupamento de 30 ativistas (Brasil, Argentina, Paraguai, Equador, Colômbia, Guatemala, El Salvador, Nicarágua, México, Bélgica e Estados Unidos da América), trabalharam na construção e no fortalecimento do MSP na América Latina, baseados nos princípios da Carta pela Saúde dos Povos para atingir a saúde para todos e todas. Concomitantemente, o MSP participou do III Fórum Social Mundial da Saúde (FSMS), com fluidas trocas de experiências de luta pela saúde em diferentes países das Américas. Fortaleceram a defesa da universalização da seguridade social para todos os povos. A partir do FSMS, foi encaminhada a Campanha 'SUS - Patrimônio da Humanidade' e firmado o engajamento para a realização da Conferência Internacional sobre o Desenvolvimento de Sistemas Universais. A Carta de Belém, elaborada e aprovada no encerramento do evento, documentou a Declaração Política do III FSMS6.

O FSM/2009 foi um marco para o MSP, consubstanciado por Ir. Anne e pelo MSP Brasil, e consolidado a partir do curso de ativistas IPHU/MSP/2008. Logo depois, no Rio de Janeiro, Ir. Anne voltou a se conectar num encontro para afinar agendas e ampliar a atuação 
do MSP nas várias regiões do Brasil. Além do MSP de Nina Rodrigues e do 'embrião' do MSP urbano, Ir. Anne vem, junto com outros ativistas, tentando incorporar uma certa organicidade ao MSP Maranhão. E a incentivar que o mesmo aconteça em Belém e mais além. Durante a IV Assembleia Mundial de Saúde dos Povos, ocorrida em 2018, cada delegado brasileiro presente em Bangladesh recebeu um exemplar traduzido da Carta MSP, material este cuidadosamente enviado pela Irmã Anne.

Ir. Anne reforça que o MSP Maranhão tem quase 19 anos de contínua atividade. Alguns membros iniciaram, outros ativistas se agregaram, e o trabalho continuou com pessoas que entraram e saíram. Assim, o trabalho nunca ficou parado. Ela diz também que, com a idade que está, tem que ser realista e aceitar os limites com alegria. Anima-se que o MSP de São Luís assume muito mais responsabilidades, somando-se ao compromisso de tantos outros aliados. Segue a organizar seu arquivo sobre a história do MSP, em geral, e do Maranhão, em particular. Parte dele subsidiou este artigo. Espera que ativistas da saúde estejam cada vez mais ao lado do povo na luta contra as injustiças. Hoje, mais do que nunca, com as reais ameaças às conquistas sociais no Brasil e no mundo, diz que o planejamento adequado começa com o povo, que é preciso tomar cuidado para que a ação acadêmica não se sobreponha à ação popular. Finaliza com a assertiva de que a revolução popular se faz com o povo.

\section{Colaboradores}

Torres MGM (0000-0001-5847-6456)*, Pereira AAC (0000-0002-6452-5493)*, Conceição TS (0000-0003-0971-4328)*, Miranda VB (0000-0003-3739-9038)* e Borges WD (00000002-7671-7855)* contribuíram igualmente na elaboração do manuscrito. 


\section{Referências}

1. Organização Mundial da Saúde. Conferência Internacional sobre Cuidados Primários de Saúde: Declaração de Alma-Ata, 1978 [internet]. Brasília, DF: Ministério da Saúde; 2002. [acesso em 2019 jan 3]. Disponível em: http://bvsms.saude.gov.br/bvs/publicacoes/declaracao_alma_ata.pdf.

2. Movimento Saúde dos Povos. Carta dos Povos Pela Saúde [internet], 2000. [acesso em 2019 maio 20]. Disponível em https://phmovement.org/the-peoples-charter-for-health/.

3. People's Health Movement. Carta Popular da Saúde [internet]. 2000. [acesso em 2019 maio 20]. Disponível em https://phmovement.org/the-peoples-charter-for-health/.

4. Movimento dos Trabalhadores Rurais Sem Terra. MST realiza prêmio Luta pela Terra e homenageia 22 lutadores [internet]. 2015. [acesso em 2019 maio 25]
Disponível em: http://www.mst.org.br/2015/01/25/ mais-de-600-pessoas-participaram-do-premio-luta-pela-terra.html.

5. Azevedo E. Tauá-Mirim é das comunidades extrativistas! [internet]. Jornal Vias de Fato. 2015 [acesso em 2015 dez 12]; 5(59). Disponível em: https://viasdefato.jor.br/.

6. Centro América Andina. O Movimento pela Saúde dos Povos da América Latina no Fórum Social Mundial [internet]. 2009. [acesso em 2019 maio 25]. Disponível em: http://centroamerica-andina.blogspot. com/2009/03/o-movimento-pela-saude-dos-povos-da.html.

Recebido em 08/06/2019

Aprovado em 14/11/2019

Conflito de interesses: inexistente

Suporte financeiro: não houve 